\title{
Review Article \\ On the Importance of Nonlinear Aeroelasticity and Energy Efficiency in Design of Flying Wing Aircraft
}

\author{
Pezhman Mardanpour ${ }^{1}$ and Dewey H. Hodges ${ }^{2}$ \\ ${ }^{1}$ University of California, Los Angeles, CA 90095, USA \\ ${ }^{2}$ Georgia Institute of Technology, Atlanta, GA 30332-0150, USA \\ Correspondence should be addressed to Dewey H. Hodges; dhodges@gatech.edu
}

Received 17 August 2014; Accepted 4 December 2014

Academic Editor: Jens N. Sorensen

Copyright (c) 2015 P. Mardanpour and D. H. Hodges. This is an open access article distributed under the Creative Commons Attribution License, which permits unrestricted use, distribution, and reproduction in any medium, provided the original work is properly cited.

\begin{abstract}
Energy efficiency plays important role in aeroelastic design of flying wing aircraft and may be attained by use of lightweight structures as well as solar energy. NATASHA (Nonlinear Aeroelastic Trim And Stability of HALE Aircraft) is a newly developed computer program which uses a nonlinear composite beam theory that eliminates the difficulties in aeroelastic simulations of flexible high-aspect-ratio wings which undergoes large deformation, as well as the singularities due to finite rotations. NATASHA has shown that proper engine placement could significantly increase the aeroelastic flight envelope which typically leads to more flexible and lighter aircraft. The areas of minimum kinetic energy for the lower frequency modes are in accordance with the zones with maximum flutter speed and have the potential to save computational effort. Another aspect of energy efficiency for High Altitude, Long Endurance (HALE) drones stems from needing to minimize energy consumption because of limitations on the source of energy, that is, solar power. NATASHA is capable of simulating the aeroelastic passive morphing maneuver (i.e., morphing without relying on actuators) and at as near zero energy cost as possible of the aircraft so as the solar panels installed on the wing are in maximum exposure to sun during different time of the day.
\end{abstract}

\section{Introduction}

Over the last decade, Hodges and coworkers [1-3] at Georgia Tech have been extensively involved in aeroelastic simulation of very light and thus highly flexible aircraft for development of the next generation of unmanned aerial vehicles (UAVs) and/or High-Altitude, Long Endurance (HALE) aircraft, including flying wings. Such aircraft typically have highaspect-ratio wings with high flexibility, which leads to large deformation. Consequently, linear aeroelastic analyses are incapable of predicting the stability characteristics of such aircraft. They successfully proved that only nonlinear aeroelastic analysis provides correct information regarding the aeroelastic flight envelope of this class of aircraft $[1,4,5]$.

Nonlinear aeroelastic trim and stability of HALE aircraft, NATASHA, is a computer program developed by the authors of references $[1,4,5]$ that accommodates modeling of large deformation of high-aspect-ratio flying wings. The theory behind NATASHA is based on the geometrically exact, nonlinear, composite beam theory of Hodges [6], along with the finite-state induced flow model of Peters et al. [7].

Previous comparisons by [2] showed that results from NATASHA are in excellent agreement with well-known beam stability solutions $[8,9]$, the flutter problem of $[10]$, experimental data presented by [11], and results from well-established computer codes such as DYMORE $[12,13]$ and RCAS [14]. Mardanpour et al. [3] considered the classical cantilever wing model of Goland and Luke [15] and verified NATASHA for the behavior of the eigenvalues as well as the effect of sweep on divergence and flutter characteristics and it was shown that gravity and load factor play an important role in aeroelasticity of high-aspect-ratio wings [16].

A principal determinant of energy consumption in aircraft is drag, which must be opposed by engine thrust for the aircraft to fly. Flying wings may achieve significant drag reduction due to a smooth outer surface and the lack of a vertical tail [3]. Consequently, the performance of such aircraft may increase significantly, relative to conventional 
configurations of the same size. The potential increase of performance for this class of aircraft has inspired aeroelasticians to design new generation of aircraft based on a flying wing configuration [3]. Typical aeroelastic instability of these aircraft is body-freedom flutter when the short-period mode of the aircraft couples with the elastic bending-torsion modes $[3,17-24]$.

In another context, a morphing solar-powered flying wing can maximize the energy absorption of solar panels on the wing surfaces by changing its configuration such that the panels have highest exposure to the sun. This change in the geometry of the flying wing is highly effective in energy absorption during times just before sunset and just after sunrise, and consequently the aircraft can sustain longer flight [25]. Use of solar energy is a novel method that eliminates one of the design constraints to a considerable extent by removing the limitation on the source of energy. The morphing concept could be based on either wing morphing systems or airfoil morphing systems, or a combination of both [26]. So far in the literature, several morphing concepts and systems have been developed based on altering various geometric parameters of the wing (such as span, chord, camber, sweep, twist, and even airfoil thickness distribution) to make the aircraft suitable for different missions and flight conditions [19, 26, 26, 26-37]. The folding wing configuration has been analyzed using linear aeroelastic models [38-40] and nonlinear aeroelastic models [41, 42]. In all the mentioned works the weight of actuators and the actuation power that the morphing mechanisms require performing their task are the problematic parts of the design [26], in particular when it comes to morphing of flying wing and/or HALE aircraft.

In this paper, after a brief outline of the theory behind NATASHA, energy efficiency in aeroelastic design and simulation for flying wing configuration will be assessed as (a) a feature of the design (i.e., engine placement), which attains instability at higher speed with lighter aircraft structure, (b) a methodology that helps to decrease computational effort required for determining favorable locations for engine placement with the potential of higher flutter speed, and (c) a scheme to passively morph a solar-powered flying wing, so that exposure to the sun of solar panels distributed on the wings is maximized for higher absorption of solar energy at specific times of the day.

\section{Theory}

2.1. Nonlinear Composite Beam Theory. The fully intrinsic nonlinear composite beam theory [6] is based on geometrically exact first-order partial differential equations of motion for the beam that are independent of displacement and rotation variables. They contain variables that are expressed in the bases of the reference frames of the undeformed and deformed beams, $b\left(x_{1}\right)$ and $B\left(x_{1}, t\right)$, respectively; see Figure 1. These geometrically exact equations are written in terms of force, moment, velocity, and angular velocity, and they contain no nonlinearities higher than second degree in the unknowns. The equations of motion are

$$
F_{B}^{\prime}+\widetilde{K}_{B} F_{B}+f_{B}=\dot{P}_{B}+\widetilde{\Omega}_{B} P_{B}
$$

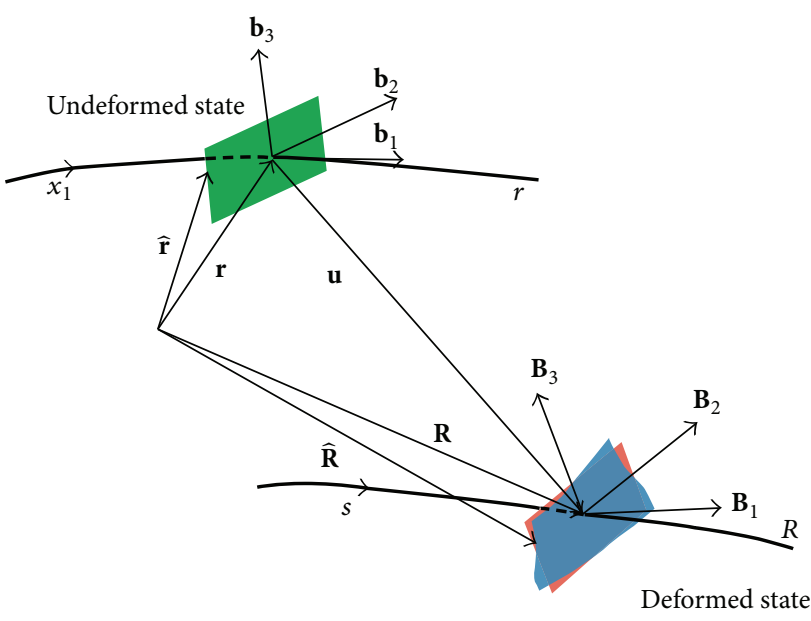

FIgURE 1: Sketch of beam kinematics.

$$
\begin{aligned}
M_{B}^{\prime} & +\widetilde{K}_{B} M_{B}+\left(\widetilde{e}_{1}+\widetilde{\gamma}\right) F_{B}+m_{B} \\
& =\dot{H}_{B}+\widetilde{\Omega}_{B} H_{B}+\widetilde{V}_{B} P_{B},
\end{aligned}
$$

where the generalized strains and velocities are related to stress resultants and moments by the structural constitutive equations

$$
\left\{\begin{array}{l}
\gamma \\
\kappa
\end{array}\right\}=\left[\begin{array}{cc}
R & S \\
S^{T} & T
\end{array}\right]\left\{\begin{array}{c}
F_{B} \\
M_{B}
\end{array}\right\}
$$

and the inertial constitutive equations

$$
\left\{\begin{array}{c}
P_{B} \\
H_{B}
\end{array}\right\}=\left[\begin{array}{cc}
\mu \Delta & -\mu \tilde{\xi} \\
\mu \tilde{\xi} & I
\end{array}\right]\left\{\begin{array}{c}
V_{B} \\
\Omega_{B}
\end{array}\right\} .
$$

Finally, strain- and velocity-displacement equations are used to derive the intrinsic kinematical partial differential equations [6], which are given as

$$
\begin{gathered}
V_{B}^{\prime}+\widetilde{K}_{B} V_{B}+\left(\widetilde{e}_{1}+\widetilde{\gamma}\right) \Omega_{B}=\dot{\gamma}, \\
\Omega_{B}^{\prime}+\widetilde{K}_{B} \Omega_{B}=\dot{\kappa} .
\end{gathered}
$$

In this set of equations, $F_{B}$ and $M_{B}$ are column matrices of cross-sectional stress and moment resultant measures in the $B$ frame, respectively; $V_{B}$ and $\Omega_{B}$ are column matrices of cross-sectional frame velocity and angular velocity measures in the $B$ frame, respectively; $P_{B}$ and $H_{B}$ are column matrices of cross-sectional linear and angular momentum measures in the $B$ frame, respectively; $R, S$, and $T$ are $3 \times 3$ partitions of the cross-sectional flexibility matrix; $\Delta$ is the $3 \times 3$ identity matrix; $I$ is the $3 \times 3$ cross-sectional inertia matrix; $\xi$ is $\left\lfloor\begin{array}{lll}0 & \xi_{2} & \xi_{3}\end{array}\right\rfloor^{T}$ with $\xi_{2}$ and $\xi_{3}$ being position coordinates of the cross-sectional mass center with respect to the reference line; and $\mu$ is the mass per unit length. Note that the tilde notation $\widetilde{()}$ denotes the antisymmetric $3 \times 3$ matrix associated with the column matrix over which the tilde is placed; ( ) denotes the partial derivative with respect to time; and ()$^{\prime}$ denotes the 
partial derivative with respect to the axial coordinate, $x_{1}$. More details about these equations can be found in [43].

This is a complete set of first-order, partial differential equations. To solve this complete set of equations, one may eliminate $\gamma$ and $\kappa$ using (2) and $P_{B}$ and $H_{B}$ using (3). Then, 12 boundary conditions are needed, in terms of force $\left(F_{B}\right)$, moment $\left(M_{B}\right)$, velocity $\left(V_{B}\right)$, and angular velocity $\left(\Omega_{B}\right)$. The maximum degree of nonlinearities is only two, and because displacement and rotation variables do not appear, singularities and other concerns related to finite rotation are avoided.

If needed, the position and the orientation can be calculated as postprocessing operations by integrating

$$
\begin{aligned}
r_{i}^{\prime} & =C^{i b} e_{1}, \\
r_{i}+u_{i}^{\prime} & =C^{i B}\left(e_{1}+\gamma\right), \\
\left(C^{b i}\right)^{\prime} & =-\tilde{k} C^{b i}, \\
\left(C^{B i}\right)^{\prime} & =-(\widetilde{k}+\widetilde{\kappa}) C^{B i},
\end{aligned}
$$

where $C^{i b}$ is the transformation matrix from undeformed frame of reference $b$ to the inertial frame of reference $i$ and $C^{i B}$ is the transformation matrix from deformed frame of reference $B$ to the inertial frame of reference $i$.

2.2. Finite-State Induced Flow Model of Peters et al. The two-dimensional finite-state aerodynamic model of Peters et al. [7] is a state-space, thin-airfoil, inviscid, incompressible approximation of an infinite-state representation of the aerodynamic loads, which accounts for induced flow in the wake and apparent mass effects, using known airfoil parameters. It accommodates large motion of the airfoil as well as deflection of a small trailing edge flap $\left( \pm 6^{\circ}\right)$. Although the two-dimensional version of this theory does not account for three-dimensional effects associated with the wing tip, published data $[2,7]$ show that this theory is a suitable choice for representing the aerodynamic loads acting on high-aspect ratio wings. Expressions for lift, drag, and pitching moment at the quarter-chord are given by

$$
\begin{aligned}
L_{\text {aero }}= & \rho b V_{T}^{2}\left(c_{l_{0}}+c_{l_{\alpha}} \sin \alpha+c_{l_{\beta}} \beta\right)+\rho b V_{T} V_{a_{2}} c_{l_{\alpha}} \alpha_{\text {rot }} \cos \alpha, \\
D_{\text {aero }}= & \rho b V_{T}^{2} c_{d_{0}}+\rho b V_{T} V_{a_{2}} c_{l_{\alpha}} \alpha_{\text {rot }} \sin \alpha, \\
M_{\text {aero }}= & 2 \rho b^{2} V_{T}^{2}\left(c_{m_{0}}+c_{m_{\alpha}} \sin \alpha+c_{m_{\beta}} \beta\right) \\
& -\frac{\rho b^{2} V_{T} V_{a_{2}} c_{l_{\alpha}} \alpha_{\text {rot }}}{2},
\end{aligned}
$$

where

$$
\begin{gathered}
V_{T}=\sqrt{V_{a_{2}}^{2}+V_{a_{3}}^{2}}, \\
\sin \alpha=\frac{-V_{a_{3}}}{V_{T}}, \\
\alpha_{\text {rot }}=\frac{\Omega_{a_{1}} b / 2}{V_{T}}
\end{gathered}
$$

and $V_{a_{2}}, V_{a_{3}}$ are the measure numbers of $V_{a}$ and $\beta$ is the flap deflection. The effects of unsteady wake (induced flow) and apparent mass appear as $\lambda_{0}$ and acceleration terms in the force and moment equations given as

$$
\begin{aligned}
& f_{a}=\rho b\left\{\begin{array}{c}
0 \\
-\left(c_{l_{0}}+c_{l_{\beta}} \beta\right) V_{T} V_{a_{3}}+c_{l_{\alpha}}\left(V_{a_{3}}+\lambda_{0}\right)^{2}-c_{d_{0}} V_{T} V_{a_{2}} \\
\left(c_{l_{0}}+c_{l_{\beta}} \beta\right) V_{T} V_{a_{2}}-\frac{c_{l_{\alpha}} \dot{V}_{a_{3}} b}{2}-c_{l_{\alpha}} V_{a_{2}}\left(V_{a_{3}}+\lambda_{0}-\frac{\Omega_{a_{1}} b}{2}\right)-c_{d_{0}} V_{T} V_{a_{3}}
\end{array}\right\}, \\
& m_{a}=2 \rho b^{2}\left\{\begin{array}{c}
\left(c_{m_{0}}+c_{m_{\beta}} \beta\right) V_{T}^{2}-c_{m_{\alpha}} V_{T} V_{a_{3}}-\frac{b c_{l_{\alpha}} V_{a_{2}} \Omega_{a_{1}}}{8}-\frac{b^{2} c_{l_{\alpha}} \dot{\Omega}_{a_{1}}}{32}+\frac{b c_{l_{\alpha}} \dot{V}_{a_{3}}}{8} \\
0 \\
0
\end{array}\right\} .
\end{aligned}
$$

The induced flow model of Peters et al. [7] is included to calculate $\lambda_{0}$ as

$$
\begin{aligned}
{\left[A_{\text {inflow }}\right]\{\dot{\lambda}\}+\left(\frac{V_{T}}{b}\right)\{\lambda\} } & =\left(-\dot{V}_{a_{3}}+\frac{b}{2} \dot{\Omega}_{a_{1}}\right)\left\{c_{\text {inflow }}\right\}, \\
\lambda_{0} & =\frac{1}{2}\left\{b_{\text {inflow }}\right\}^{T}\{\lambda\},
\end{aligned}
$$

where $\{\lambda\}$ is the column matrix of induced flow states and $\left[A_{\text {inflow }}\right],\left\{c_{\text {inflow }}\right\}$, and $\left\{b_{\text {inflow }}\right\}$ are constant matrices derived in [7].

\section{Nonlinear Aeroelastic Trim and Stability of HALE Aircraft (NATASHA)}

NATASHA is a computer program that is based on a geometrically exact, composite beam formulation [43] and a finitestate induced flow aerodynamic model [7]. The governing equations for the structural model are geometrically exact, fully intrinsic, and capable of analyzing the dynamical behavior of a general, nonuniform, twisted, curved, anisotropic beam undergoing large deformation. The dependence of the partial differential equations on $x_{1}$ is approximated by spatial 


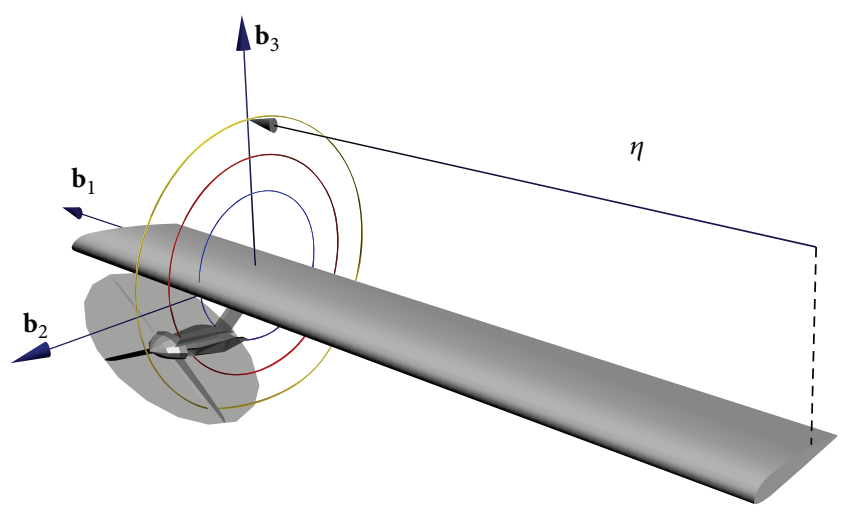

FIGURE 2: Schematic view of the wing with engine.

central differencing [5]. A discretized version of the resulting nonlinear ordinary differential equations is linearized about a state of steady motion governed by nonlinear algebraic equations which NATASHA solves to obtain the so-called trim solution, using Newton-Raphson or similar procedures [5]. This system of nonlinear aeroelastic equations, when linearized about the resulting trim state, leads to a standard eigenvalue problem, which NATASHA uses to assess stability.

\section{Effect of Engine Placement on Aeroelastic Flight Envelop}

4.1. High-Aspect-Ratio Wing. A lightweight, small-class thrust turboshaft engine (JetCat SP5) [44] with known thrust, mass, moments of inertia, and angular momentum, which operates at the cruise condition, is placed along the span of a highly flexible, high-aspect-ratio wing [16]. The engine mounts are displaced with an offset from the elastic axis parallel to the plane of the wing cross section, that is, the local $\mathbf{b}_{2}-\mathbf{b}_{3}$ plane, while orientations of the engines are maintained; see Figure 2.

In stability analysis with gravity $\left(g=9.8 \mathrm{~m} / \mathrm{s}^{2}\right)$ the wing flutters at $22.4 \mathrm{~m} / \mathrm{s}$, with a hump first bending-torsion mode and with a frequency of $12.199 \mathrm{rad} / \mathrm{sec}$ which returns to the stability region at higher speeds. At $45 \mathrm{~m} / \mathrm{s}$ the second bending-torsion with a frequency of 27.406 becomes unstable [16]. NATASHA's result for flutter characteristics captures significant increase in flutter speed, more than three times the baseline model (i.e., with engines at the root of the wing), for engines placed at $60 \%$ to $80 \%$ span, and forward of the elastic axis. Also, a significant decrease in flutter speed is observed for engine placement at $30 \%$ to $50 \%$ span and aft of the elastic axis. Here forward means in the $\mathbf{b}_{2}$ direction, and above the elastic axis means in the $\mathbf{b}_{3}$ direction; see Figures 3 and 4 .

4.2. Two-Engine Flying Wing. The geometry of the flying wing resembles the HORTEN IV $[18,20]$ and the properties were tuned [3] such that the aircraft experiences bodyfreedom flutter with the frequencies close to those of the body-freedom flutter frequency obtained from interviews with HORTEN IV pilots [20]. Two identical engines were symmetrically moved along the span, that is, in the $\mathbf{b}_{1}$

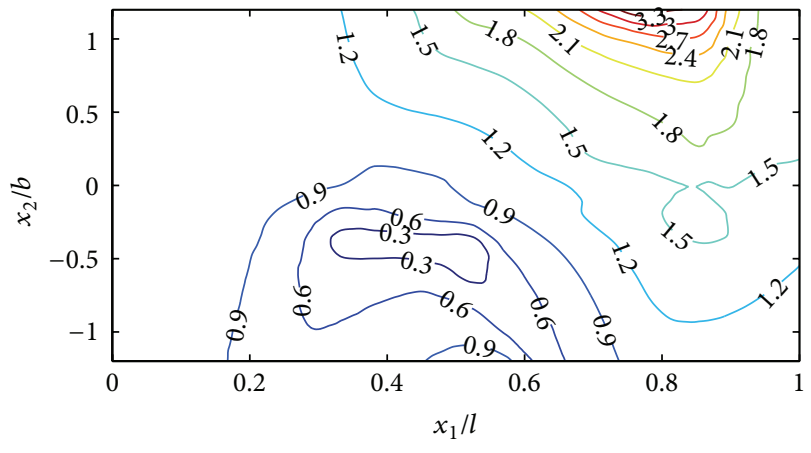

FIGURE 3: Contour of normalized flutter speed for engine placement in chordwise direction, that is, $\mathbf{b}_{2}$; considering gravity, $g=9.8 \mathrm{~m} / \mathrm{s}^{2}$.

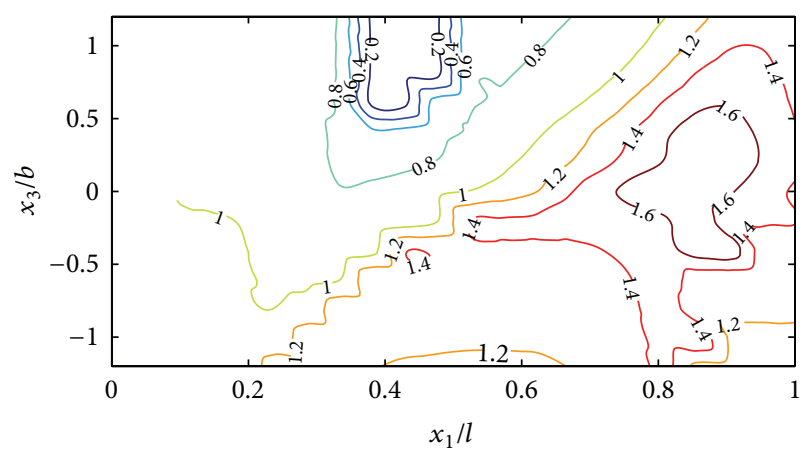

FIGURE 4: Contour of normalized flutter speed for engine placement in the vertical direction, that is, $\mathbf{b}_{3}$; considering gravity, $g=9.8 \mathrm{~m} / \mathrm{s}^{2}$.

direction, and displaced as described in Section 4.1; see Figure 5.

The effect of engine placement showed that the maximum flutter speed occurs when the engines are just outboard of $60 \%$ span; see Figure 6 . The minimum flutter speed occurs for engine placement at the wing tips. Both minima and maxima occurred when the c.g. of the engine was forward of the wing elastic axis [3]; see Figures 7 and 8.

4.3. Four-Engine Flying Wing. The four-engine configuration (see Figure 9) is an alternative because of safety and reliability considerations associated with two-engine aircraft. The engine offsets from the elastic axis are presented in polar coordinates with $\left(r_{n}, \psi_{n}\right)$ where $n$ is the engine number. Figures 10 and 11 show the variation in flutter speed for different engine placements along the span with different offsets from the elastic axis while one of the engines was kept fixed in a particular location and the other one moves along the span.

Former study showed that engine placement does not have a significant effect on the lift to drag ratio [24]. However, a noticeable increase in flutter speed is observed when engines are placed forward of the elastic axis. For these cases, as one of the engines is placed at the outboard portion of the span, flutter speed increases. A detailed study on this effect is presented in the work of Mardanpour et al. [24]. 


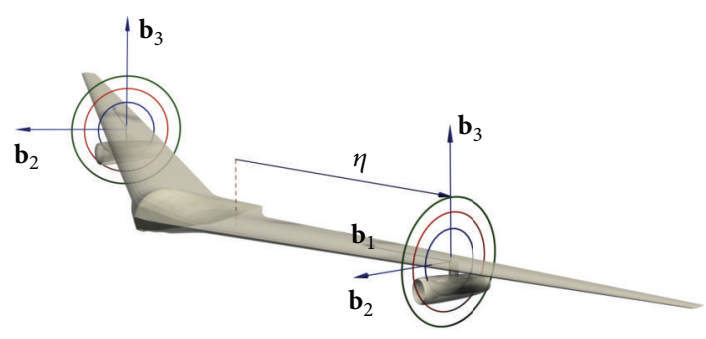

FIGURE 5: Schematic view of the two-engine flying wing.

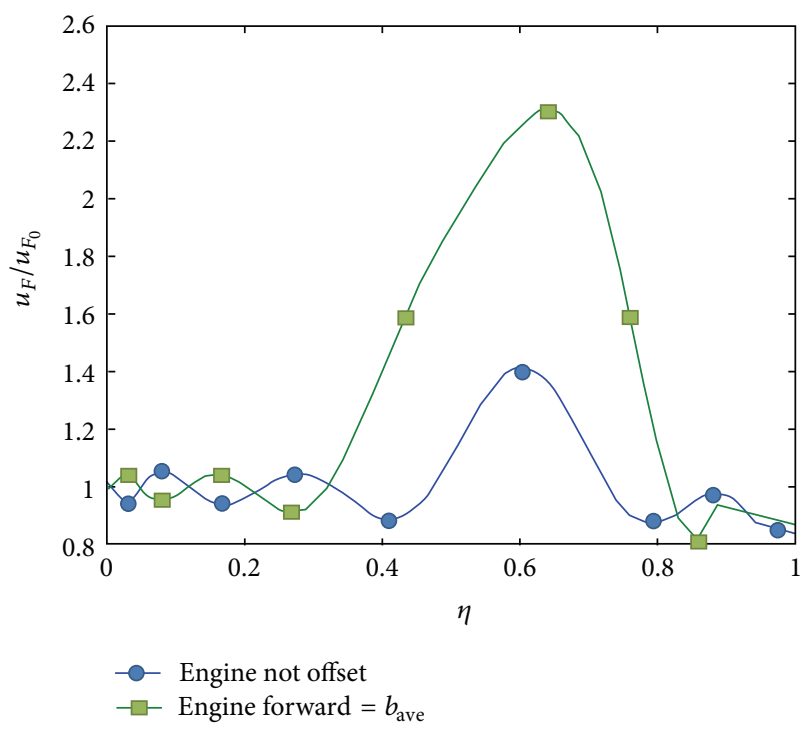

FIGURE 6: Flutter speed for engine placement along the span for two values of chordwise offset.

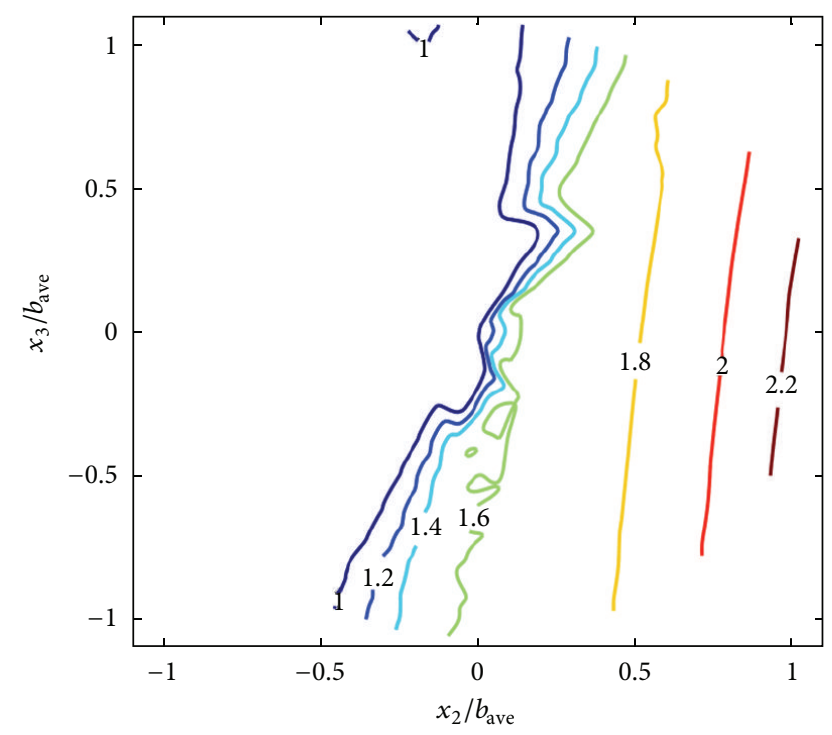

FIGURE 7: Contour of normalized flutter speed at $\eta=0.65$, twoengine flying wing.

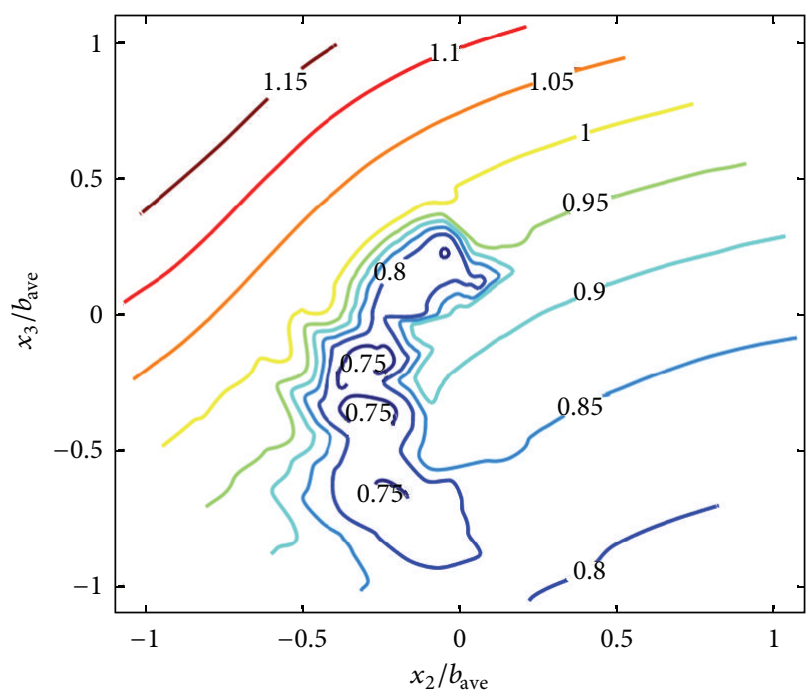

FIGURE 8: Contour of normalized flutter speed at $\eta=1$, two-engine flying wing.

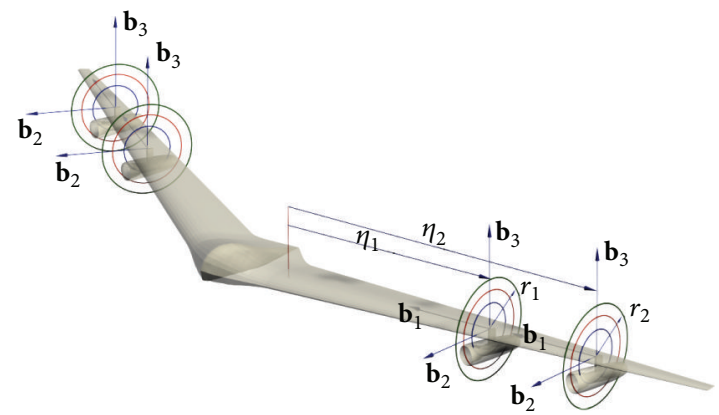

FIGURE 9: Schematic view of the four-engine flying wing.

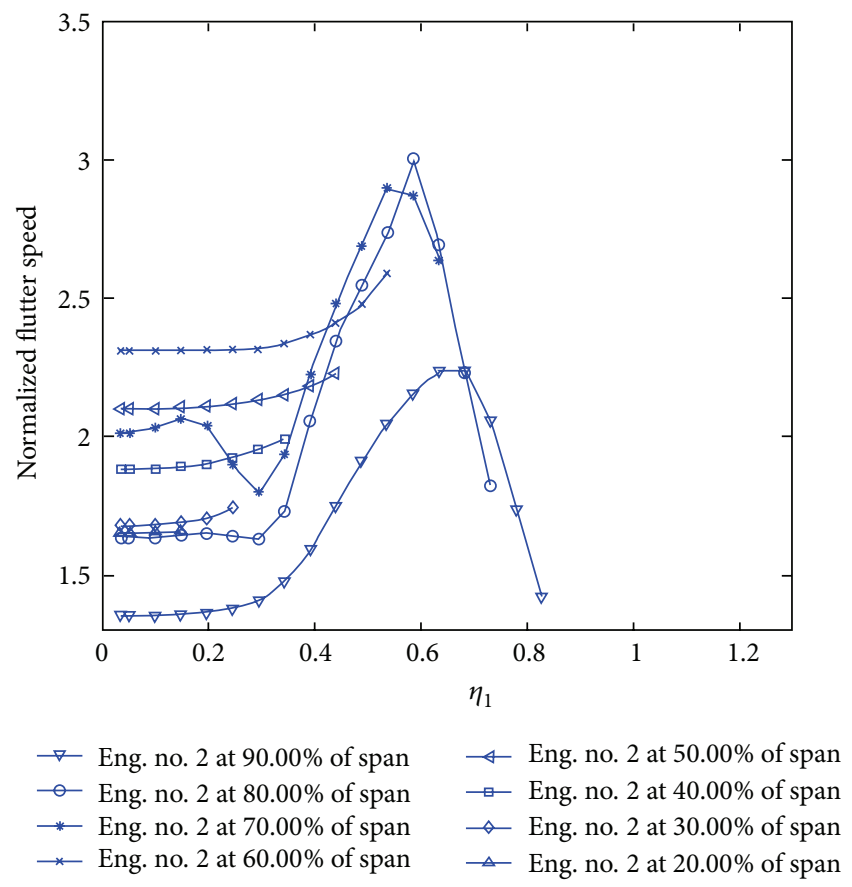

FIGURE 10: Normalized flutter speed for $r_{1}=r_{2}=0$ and $\psi_{1}=\psi_{2}=$ $0^{\circ}$. 


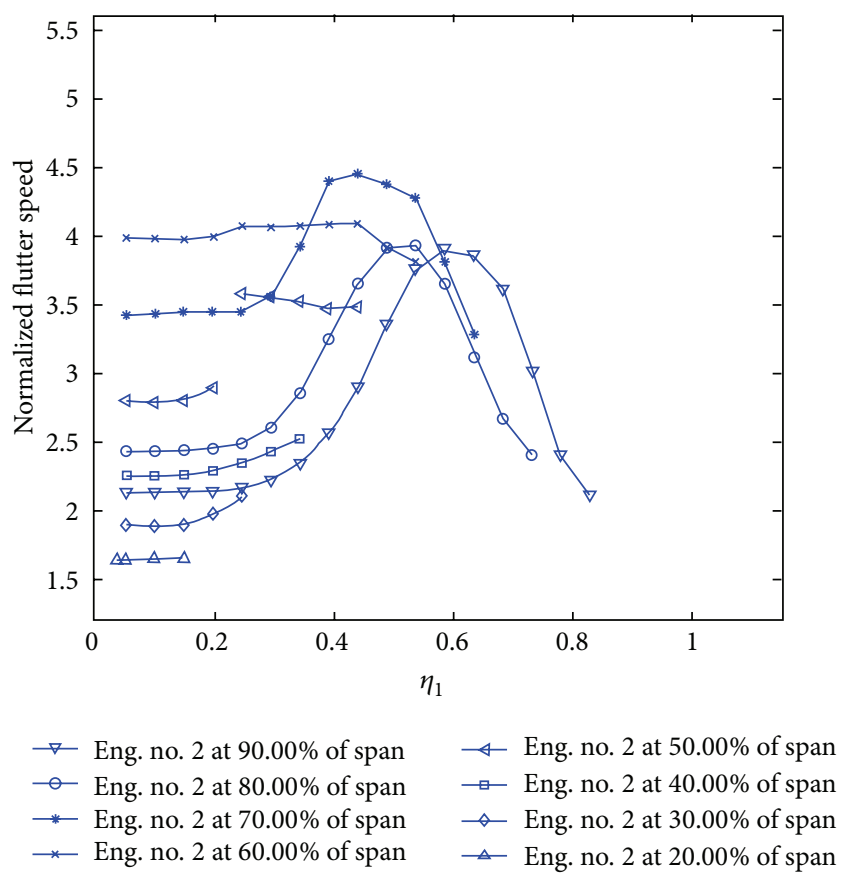

FIGURE 11: Normalized flutter speed for $r_{1}=r_{2}=0.3$ and $\psi_{1}=\psi_{2}=$ $0^{\circ}$.

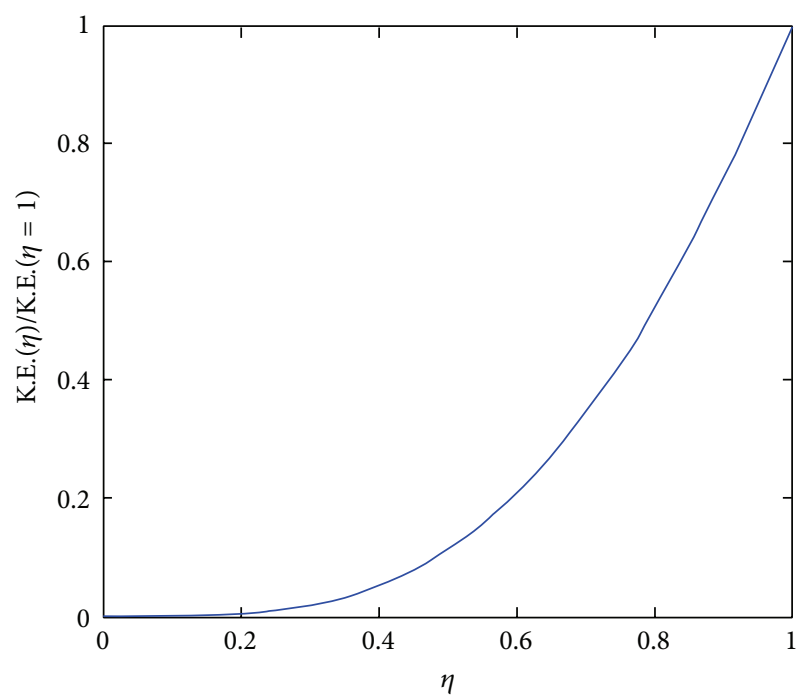

FIGURE 12: Normalized kinetic energy of the first bending mode of the wing.

\section{Area of Minimum Kinetic Energy Density of the Mode}

Engine placement at certain location has the potential to increase the flutter speed in two ways. One is the location where lower frequency flutter mode could be relegated to a higher frequency mode and the other is the location where the fluid structure interaction is decreased. Both criteria could be met at the area of minimum kinetic energy of the mode. In other words, engine placement at the area of minimum kinetic energy of the modes has the potential to

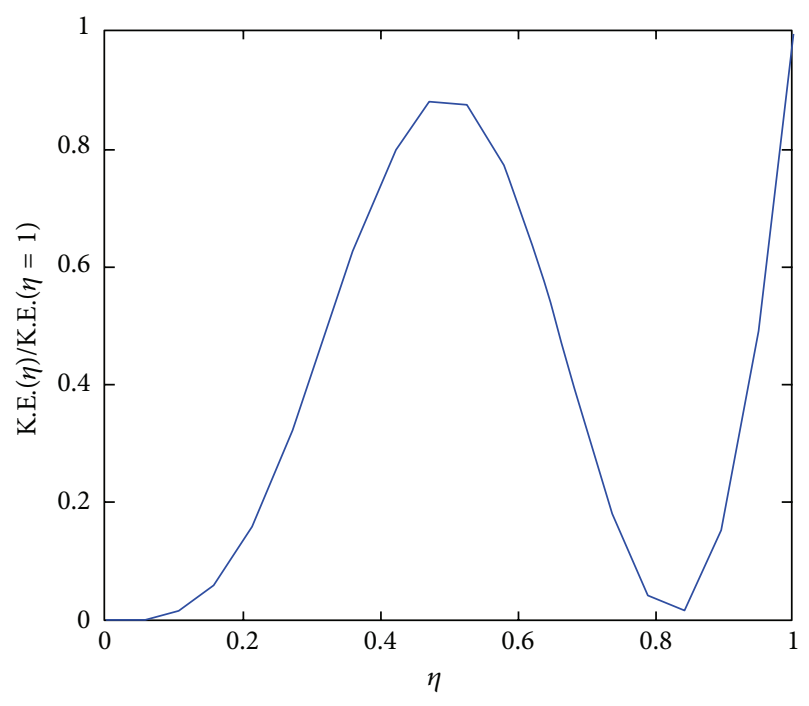

FIGURE 13: Normalized kinetic energy of the second bending mode of the wing.

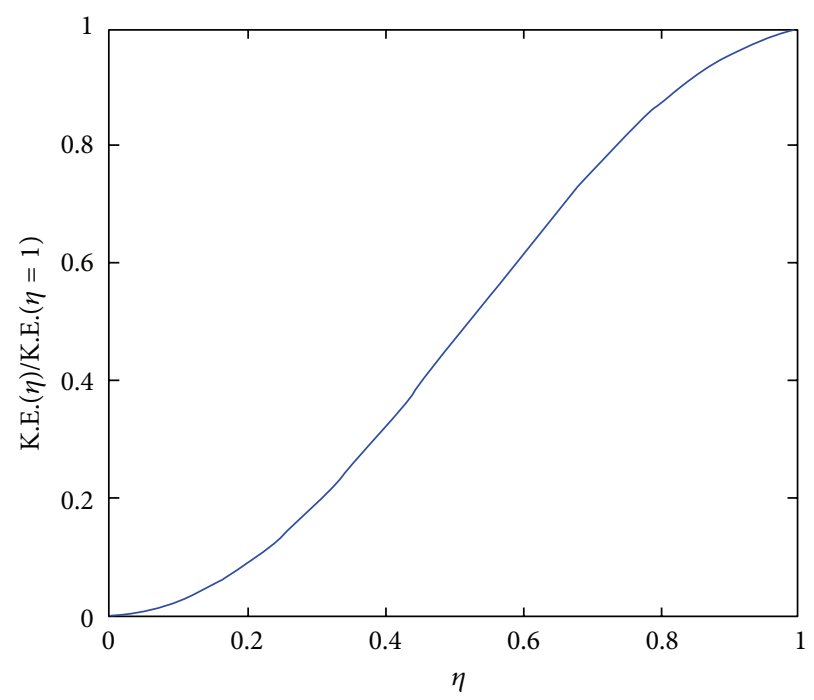

FIGURE 14: Normalized kinetic energy of the first torsion mode of the wing.

decrease fluid-structure interaction and enforce the structure to flutter at a higher mode [16]. In case of the high-aspectratio wing presented in Section 4.1, the area of minimum kinetic energy density of the first two bending and torsion modes of the wing, in the absence of engines, gravitational, and aerodynamic forces, is presented in Figures 12-15. For the first bending and torsion modes this area is a minimum at the root of the wing; see Figures 12-14. For the second bending mode the area of minimum kinetic energy density of the mode has a local minimum outboard of the $85 \%$ span, and for second torsion mode this minimum moves to the region between $70 \%$ and $90 \%$ span; see Figures 13-15. For engine placement forward of the elastic axis, the unstable mode contains a combination of first and second bending along with second torsion; and when the engines are placed around 50\% 


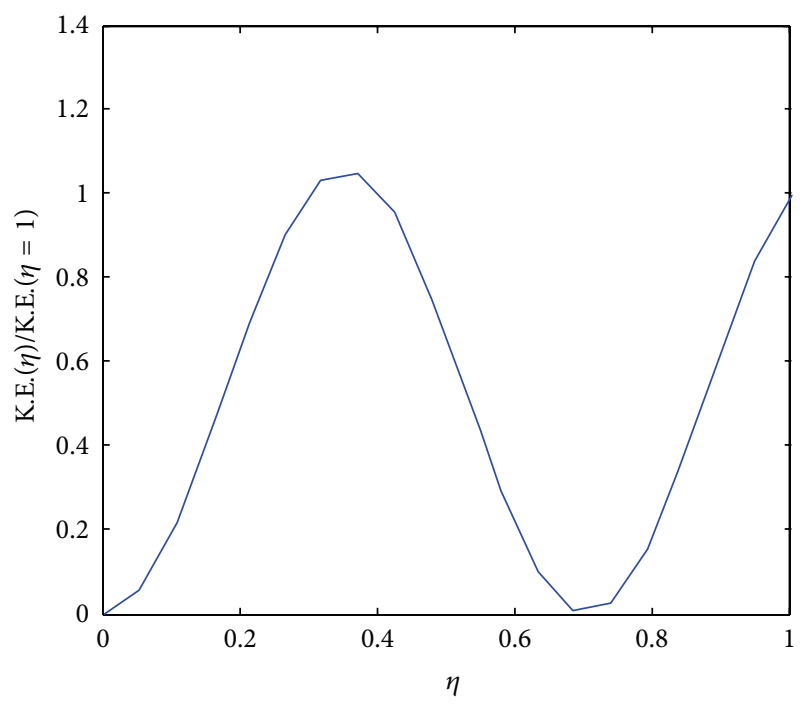

FIGURE 15: Normalized kinetic energy of the second torsion mode of the wing.

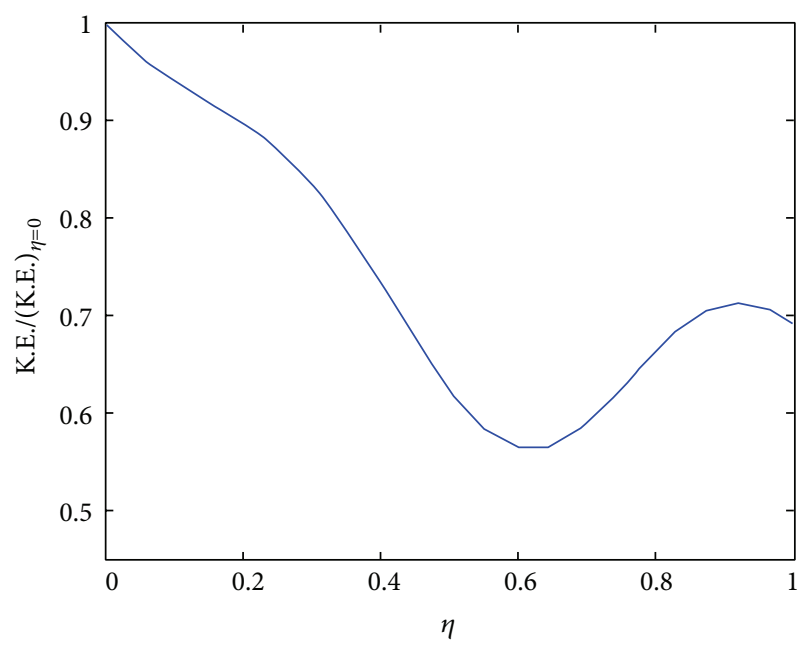

FIGURE 16: Normalized kinetic energy of the first elastic free-free coupled bending-torsion mode of the flying wing.

to $70 \%$ span, there is a noticeable increase in flutter speed. This is close to the area of minimum kinetic energy of the second bending and torsion modes; see Figures 13-15.

To further explore this possibility, the same analysis is performed for the two-engine and four-engine configurations. Figure 16 depicts the kinetic energy distribution of the symmetric free-free mode of the bare wing for the case study presented in Section 4.2. One can see that the point of the minimum kinetic energy is just outboard of $60 \%$ span [3].

In case of the four-engine configuration, for engine placement forward of the elastic axis, the unstable mode contains a combination of first, second, and third bending modes [24]; and when the engines are placed around 60\% to $80 \%$ span, there is a noticeable increase in flutter speed. This area is close to the area of minimum kinetic energy of the first three bending modes; see Figures 17, 18, and 19.

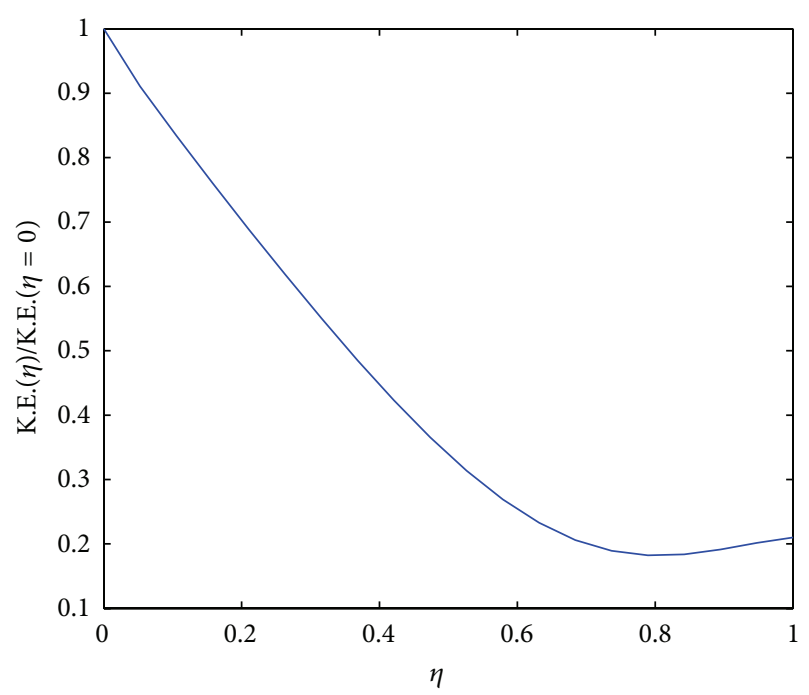

FIGURE 17: Normalized kinetic energy of the symmetric first freefree elastic bending mode of the flying wing.

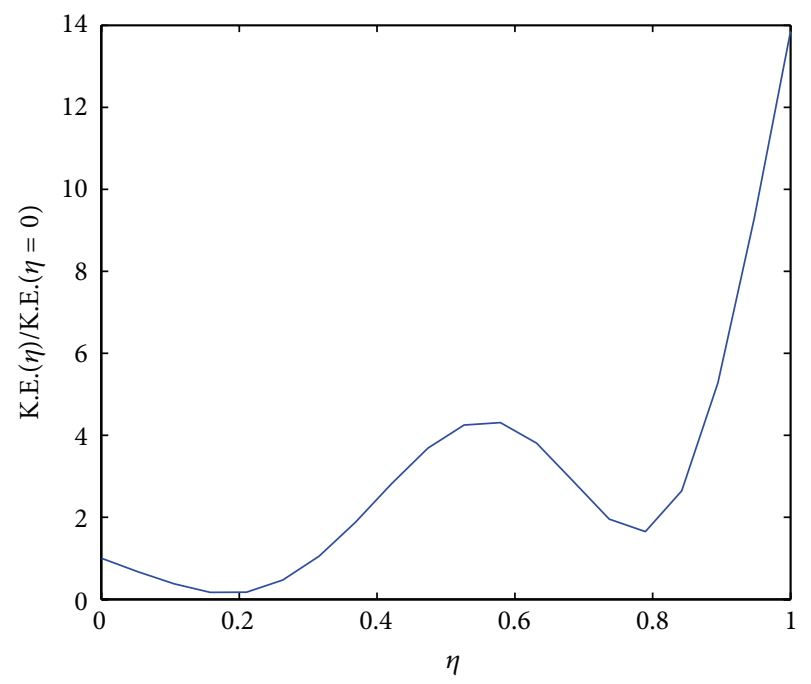

FIGURE 18: Normalized kinetic energy of the symmetric second freefree elastic bending mode of the flying wing.

\section{Passive Morphing of Solar Powered Flying Wing Aircraft}

HALE aircraft can achieve sustained, uninterrupted flight time if they use solar power. Wing morphing of solarpowered HALE aircraft can significantly increase solar energy absorbency [25]. An example of the kind of morphing considered in this chapter requires the wings to fold so as to orient a solar panel to be hit more directly by the sun's rays at specific times of the day [25]; see Figure 20.

In this study solar-powered HALE flying wing aircraft are modeled with three beams with lockable hinge connections. There were four identical engines with prescribed mass, inertia, and angular momentum placed at outer portion of the beams with zero offset from the elastic axis; see Figure 21. 


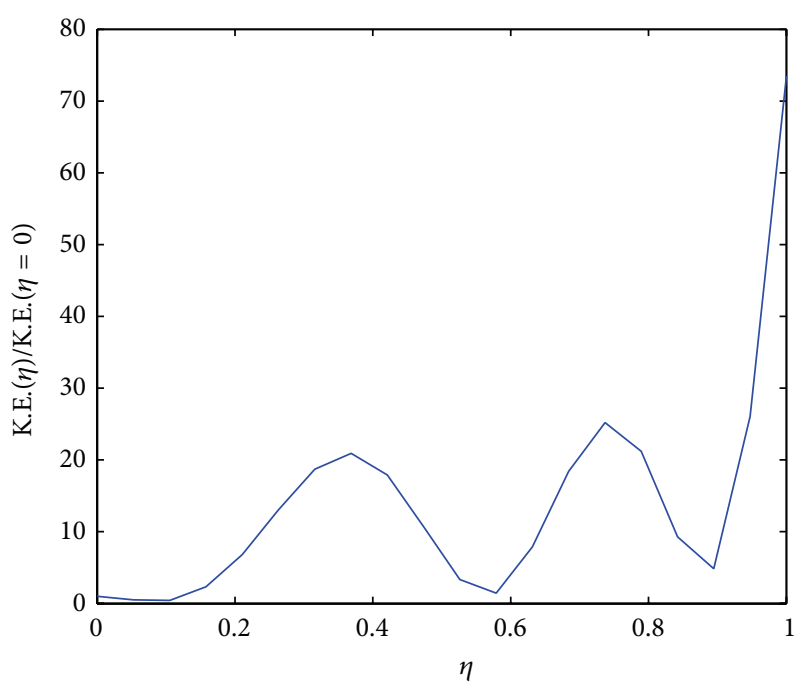

FIGURE 19: Normalized kinetic energy of the symmetric third freefree elastic bending mode of the flying wing.

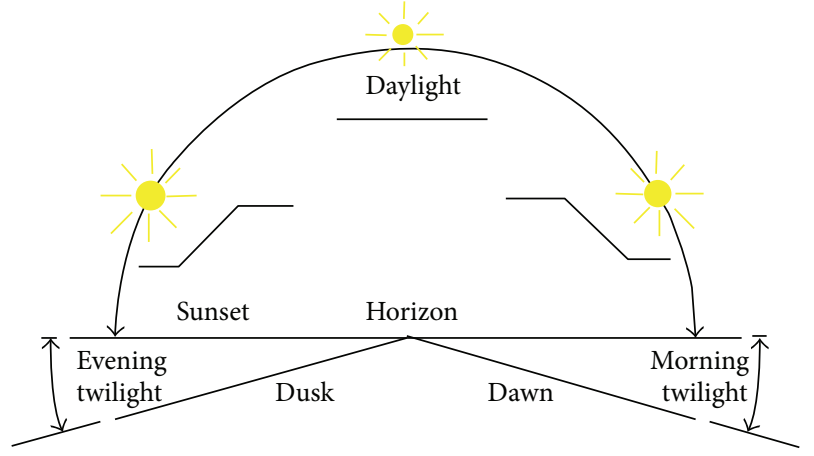

FIGURE 20: Schematic view of the solar-powered flying wing morphing and sun position.

Three sets of flaps are distributed on the wings: one set (set 1) is on the side wings; the middle beam was divided into equal portions for the two other sets of flaps (sets 2 and 3); see Figures 21 and 22.

Such aircraft are shown to be capable of morphing passively, so that the solar panels are oriented toward the sun using only input from flight control surfaces and engine thrust. The analysis underlying NATASHA was extended to include the ability to simulate morphing of the aircraft into a "Z" configuration; see Figure 22. Because of the "long endurance" feature of HALE aircraft, such morphing needs to be done without relying on actuators and at as near zero energy cost as possible.

For simulation of this complete maneuver, a schedule of "trim conditions" is solved using the trim analysis in NATASHA. The resulting control history (see Figure 23) is then interpolated from these solutions and input into NATASHA simulation. The stability analysis of the trim conditions showed that this aircraft is aeroelastically stable and the instabilities are flight dynamics modes with very small nonoscillatory eigenvalues [25].

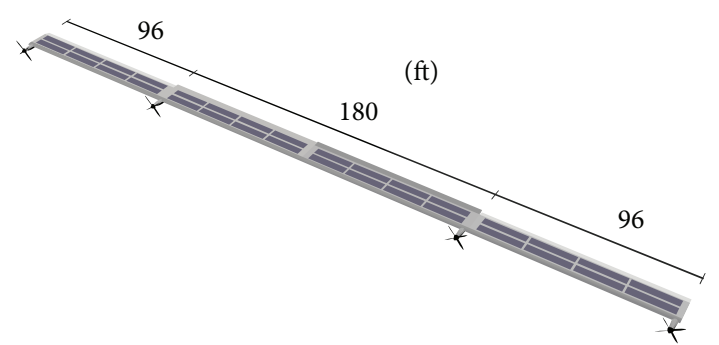

FIGURE 21: Geometry of the solar-powered flying wing.

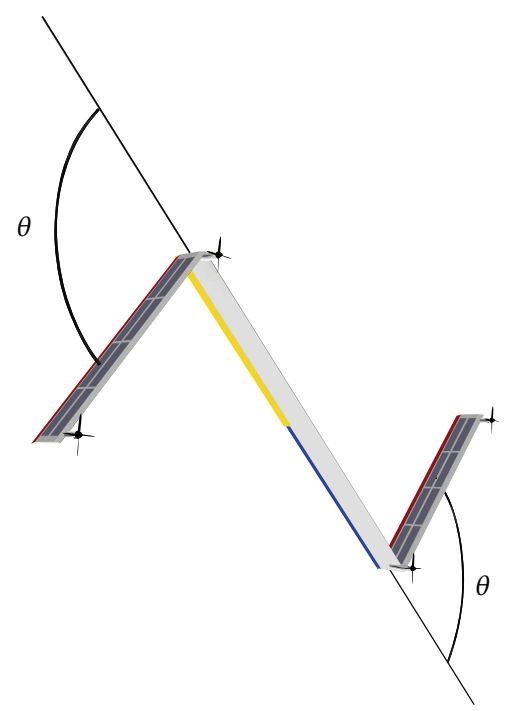

FIGURE 22: Schematic front view of the morphed configuration of the solar-powered flying wing.

Detailed systematic processes for trim and timemarching for a passively morphing flying wing are presented in [25].

\section{Concluding Remarks}

Energy efficiency in aeroelastic design and simulation of flying wings may be enhanced by appropriate choice of design features, for example, engine placement, which attains instability at higher speed with lighter aircraft structure. For this purpose, a very flexible high-aspect-ratio wing, which displays geometrically nonlinear behavior in subsonic flow, is analyzed using NATASHA. The effect of engine placement along the span with various offsets from the elastic axis is studied using a small-class, lightweight thruster (e.g., JetCat SP5) operating at the cruise condition. A significant decrease in flutter speed is observed for engine placement at $30 \%$ to $50 \%$ span, aft of the elastic axis, that is, in the negative $\mathbf{b}_{2}$ direction, and above the elastic axis, that is, in the positive $\mathbf{b}_{3}$ direction. The same effect for a two-engine flying wing configuration, with geometry similar to the Horten IV, was studied and because of safety and reliability considerations associated with two-engine aircraft the analogy was extended to a four-engine configuration. For the case of a two-engine 


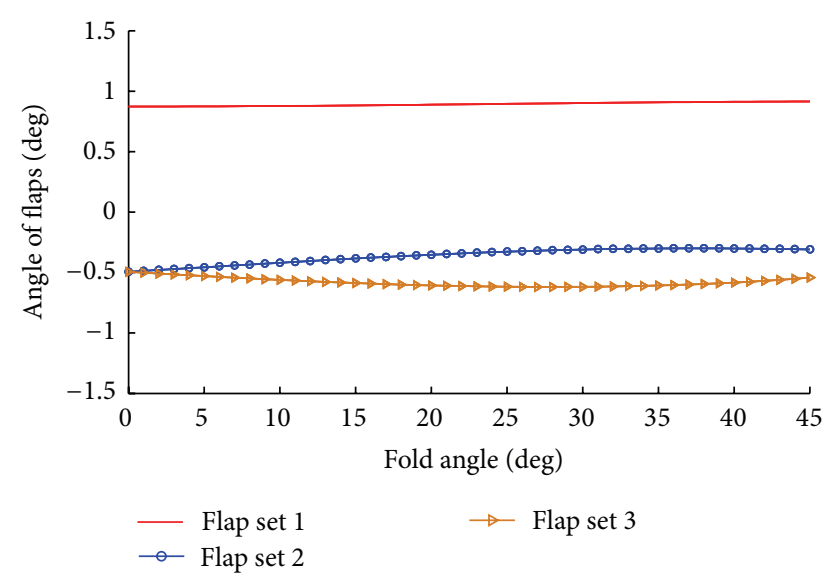

FIGURE 23: Deflection of flaps versus angle of morph.

configuration, the maximum flutter speed occurs when the engines are just outboard of $60 \%$ span. The minimum flutter speed occurs for engine placement at the wing tips. Both minima and maxima occurred when the c.g. of the engine was forward of the wing elastic axis. In case of a fourengine configuration, a noticeable increase in flutter speed is observed when engines are placed forward of the elastic axis. For these cases, as one of the engines is placed at the outboard portion of the span, flutter speed increases. For engine placement aft of the elastic axis, flutter speed increases when both engines are close to the root.

In the absence of engines and aerodynamic and gravitational forces, NATASHA found that (a) for a high-aspectratio wing, the minimum kinetic energy region of the second bending mode has a local maximum around $45 \%$ to $55 \%$ span and a local minimum at $80 \%$ to $90 \%$ span and the second torsion mode has these minima at $30 \%$ to $40 \%$ and $65 \%$ to $75 \%$ span, (b) for a two-engine flying wing, it is very near the $60 \%$ span for the first symmetric elastic free-free bending mode, and (c) for a four-engine configuration, the minimum kinetic energy regions for the first and third bending modes are located at approximately $60 \%$ span and for the second mode, the kinetic energy has local minima around $20 \%$ and $80 \%$ span. The areas of minimum kinetic energy for these modes are in agreement with flutter calculations, which show a noticeable increase in flutter speed if engines are placed forward of the elastic axis at these regions. Knowledge of the minimum kinetic energy region thus has some potential to help the designer and could possibly lead to significant savings in computational effort.

The analysis underlying NATASHA was extended to include the ability to simulate morphing of the aircraft using a new set of trim and kinematical differential equations. An example of the kind of morphing considered in this study requires the wings to fold so as to orient solar panels to be hit more directly by the sun's rays at specific times of the day. Because of the "long endurance" feature of HALE aircraft, such morphing needs to be done with as near zero energy cost as possible, that is, without relying on actuators at the hinges but instead using aerodynamic forces, controlled by flap deployments, and engine thrusts. The three-wing, solarpowered HALE aircraft morphs passively into a Z-shaped configuration while local bending moments are zeroed out at the hinge connection points, but with the hinges locked with the fold angle held at zero degrees while the aircraft morphs. The morphing motion is brought to a stop before the hinges are again locked.

\section{Future Work}

The present aeroelastic simulation of passive wing morphing neglects the effects of hinge stiffness and damping, but their addition is planned for a later work to enhance the realism of the model. The addition of hinge damping will allow energy dissipation to be taken into account, and it is expected that incorporation of a spring-restrained hinge may facilitate passive morphing and gust response of the aircraft during the morphing phases. Other recommendations for future studies include addition of the 3D Peters aerodynamic model to account for moderate aspect-ratio wings and axial flow. Such an aerodynamic model will extend the validity of analysis done by NATASHA to rotary wings.

In the present effort the effect of engine aerodynamics has not been considered. Explicit formulation of the same would require the use of $3 \mathrm{D}$ computational fluid dynamic (CFD) model. At this present moment, to the best of the author's knowledge accurate simulation of the engine aerodynamics will retain the qualitative aspect of the current analysis but might lead to some quantitative improvements. Another aspect worthy of future investigation is to account for the flexibility of the engine nacelle and mount. It will be interesting to outline whether consideration of their flexibility and the resulting dynamics affects the aeroelastic behavior of the aircraft. Also, the inertial properties and flexibilities of control surfaces are not studied, including those in NATASHA that facilitates the simulations.

\section{Nomenclature}

a: Deformed beam aerodynamic frame of reference

$b$ : Undeformed beam cross-sectional frame of reference

$B$ : Deformed beam cross-sectional frame of reference

$\mathbf{b}_{i}$ : Unit vectors in undeformed beam cross-sectional frame of reference $(i=1,2,3)$

$\mathbf{B}_{i}$ : Unit vectors of deformed beam cross-sectional frame of reference $(i=1,2,3)$

c: Chord

$c_{m \beta}$ : Derivative of pitch moment coefficient with respect to flap deflection $(\beta)$

$c_{l \alpha}$ : Derivative of lift coefficient with respect to angle of attack $(\alpha)$

$c_{l \beta}$ : Derivative of lift coefficient with respect to flap deflection $(\beta)$ 
$e_{1}: \quad$ Column matrix $\left\lfloor\begin{array}{lll}1 & 0 & 0\end{array}\right]^{T}$

$e$ : Offset of aerodynamic center from the origin of frame of reference along $\mathbf{b}_{2}$

$f$ : Column matrix of distributed applied force measures in $\mathbf{B}_{i}$ basis

$F$ : Column matrix of internal force measures in $\mathbf{B}_{i}$ basis

g: Gravitational vector in $\mathbf{B}_{i}$ basis

$H$ : Column matrix of cross-sectional angular momentum measures in $\mathbf{B}_{i}$ basis

$i$ : Inertial frame of reference

$\mathbf{i}_{i}$ : Unit vectors for inertial frame of reference $(i=1,2,3)$

I: Cross-sectional inertia matrix

$k$ : Column matrix of undeformed beam initial curvature and twist measures in $\mathbf{b}_{i}$ basis

$K$ : Column matrix of deformed beam curvature and twist measures in $\mathbf{B}_{i}$ basis

$m$ : Column matrix of distributed applied moment measures in $\mathbf{B}_{i}$ basis

$M$ : Column matrix of internal moment measures in $\mathbf{B}_{i}$ basis

$P$ : Column matrix of cross-sectional linear momentum measures in $\mathbf{B}_{i}$ basis

$r$ : Column matrix of position vector measures in $\mathbf{b}_{i}$ basis

$R: \quad 3 \times 3$ partition of the cross-sectional flexibility matrix

$S: \quad 3 \times 3$ partition of the cross-sectional flexibility matrix

T: $3 \times 3$ partition of the cross-sectional flexibility matrix

$u$ : Column matrix of displacement vector measures in $\mathbf{b}_{i}$ basis

$V: \quad$ Column matrix of velocity measures in $\mathbf{B}_{i}$ basis

$x_{1}$ : Axial coordinate of beam

$\beta$ : $\quad$ Trailing edge flap angle

$\Delta: \quad$ Identity matrix

$\gamma$ : Column matrix of $1 \mathrm{D}$ generalized force strain measures

$\kappa: \quad$ Column matrix of elastic twist and curvature measures (moment strain)

$\lambda_{0}$ : Induced flow velocity

$\mu$ : $\quad$ Mass per unit length

$\xi$ : Column matrix of center of mass offset from reference line in $\mathbf{b}_{i}$ basis

$\Omega$ : Column matrix of cross-sectional angular velocity measures in $\mathbf{B}_{i}$ basis

( ) $)^{\prime}$ : Partial derivative of () with respect to $x_{1}$

(): Partial derivative of ( ) with respect to time

$\widehat{():}$ Nodal variable

()$_{F}$ : At flutter point.

\section{Conflict of Interests}

The authors declare that there is no conflict of interests regarding the publication of this paper.

\section{Acknowledgments}

This work was supported in part by the Air Force Research Laboratory Contract FA8650-06-D-3624/000708 through Bihrle Applied Research, Inc., and Award ECCS-1101431 from the National Science Foundation.

\section{References}

[1] M. J. Patil and D. H. Hodges, "On the importance of aerodynamic and structural geometrical nonlinearities in aeroelastic behavior of high-aspect-ratio wings," Journal of Fluids and Structures, vol. 19, no. 7, pp. 905-915, 2004.

[2] Z. Sotoudeh, D. H. Hodges, and C. S. Chang, "Validation studies for aeroelastic Trim and Stability analysis of highly flexible aircraft," Journal of Aircraft, vol. 47, no. 4, pp. 1240-1247, 2010.

[3] P. Mardanpour, D. H. Hodges, R. Neuhart, and N. Graybeal, "Engine placement effect on nonlinear trim and stability of flying wing aircraft," Journal of Aircraft, vol. 50, no. 6, pp. 17161725, 2013.

[4] M. J. Patil, D. H. Hodges, and C. E. S. Cesnik, "Nonlinear aeroelasticity and flight dynamics of high-altitude long-endurance aircraft," Journal of Aircraft, vol. 38, no. 1, pp. 88-94, 2001.

[5] M. J. Patil and D. H. Hodges, "Flight dynamics of highly flexible flying wings," Journal of Aircraft, vol. 43, no. 6, pp. 1790-1799, 2006.

[6] D. H. Hodges, "Geometrically-exact, intrinsic theory for dynamics of curved and twisted anisotropic beams," AIAA Journal, vol. 41, no. 6, pp. 1131-1137, 2003.

[7] D. A. Peters, S. Karunamoorthy, and W.-M. Cao, "Finite state induced flow models part I: two-dimensional thin airfoil," Journal of Aircraft, vol. 32, no. 2, pp. 313-322, 1995.

[8] S. P. Timoshenko and J. M. Gere, Theory of Elastic Stability, McGraw-Hill, New York, NY, USA, 2nd edition, 1961.

[9] G. J. Simitses and D. H. Hodges, Fundamentals of Structural Stability, Elsevier, Boston, Mass, USA, 2006.

[10] M. Goland, “The utter of a uniform cantilever wing," Journal of Applied Mechanics, vol. 12, no. 4, pp. A197-A208, 1945.

[11] E. H. Dowell, J. Traybar, and D. H. Hodges, "An experimentaltheoretical correlation study of non-linear bending and torsion deformations of a cantilever beam," Journal of Sound and Vibration, vol. 50, no. 4, pp. 533-544, 1977.

[12] O. A. Bauchau and N. K. Kang, "Multibody formulation for helicopter structural dynamic analysis," Journal of the American Helicopter Society, vol. 38, no. 2, pp. 3-14, 1993.

[13] O. A. Bauchau, "Computational schemes for flexible, nonlinear multi-body systems," Multibody System Dynamics, vol. 2, no. 2, pp. 169-225, 1998.

[14] H. Saberi, M. Khoshlahjeh, R. A. Ormiston, and M. J. Rutkowski, "RCAS overview and application to advanced rotorcraft problems," in Proceedings of the 4th Decennial Specialists' Conference on Aeromechanics, pp. 741-781, American Helicopter Society, San Francisco, Calif, USA, January 2004.

[15] M. Goland and Y. L. Luke, "The utter of a uniform wing with tip weights," Journal of Applied Mechanics, vol. 15, no. 1, pp. 13-20, 1948.

[16] P. Mardanpour, D. H. Hodges, and R. Rezvani, "Nonlinear aeroelasticity of high-aspect-ratio wings excited by timedependent thrust," Nonlinear Dynamics, vol. 75, no. 3, pp. 475500, 2014. 
[17] R. R. F. Chipman, M. Rimer, and B. Muniz, "Body-freedom utter of a 1/2-scale forward swept-wing model, an experimental and analytical study," Tech. Rep. NAS1-17102, NASA Langley Research Center, 1984.

[18] D. Gyorgy-Falvy, "Performance analysis of the 'Horten IV'; Flying Wing," in Proceedings of the 8th O.S.T.I.V. Congress, Cologne, Germany, June 1960.

[19] M. H. Love, P. S. Zink, P. A. Wieselmann, and H. Youngren, "Body freedom flutter of high aspect ratio flying wings," in Proceedings of the 46th AIAA/ASME/ASCE/AHS/ASC Structures, Structural Dynamics and Materials Conference, pp. 1808-1830, AIAA, Austin, Tex, USA, April 2005.

[20] D. Myhra, The Horten Brothers and Their All-Wing Aircraft. Schiffer Military/Aviation History, Schiffer Publications, Atglen, Pa, USA, 1998.

[21] J. R. Banerjee, "Flutter characteristics of high aspect ratio tailless aircraft," Journal of Aircraft, vol. 21, no. 9, pp. 733-736, 1984.

[22] J. R. Banerjee, "Flutter modes of high aspect ratio tailless aircraft," Journal of Aircraft, vol. 25, no. 5, pp. 473-476, 1988.

[23] J. Schweiger, O. Sensburg, and H. J. Berns, "Aeroelastic problems and structural design of a tailless CFC-sailplane," in Proceedings of the 2nd International Forum on Aeroelasticity and Structural Dynamics, pp. 457-467, Aachen, Germany, 1985.

[24] P. Mardanpour, P. W. Richards, O. Nabipour, and D. H. Hodges, "Effect of multiple engine placement on aeroelastic trim and stability of flying wing aircraft," Journal of Fluids and Structures, vol. 44, pp. 67-86, 2014.

[25] P. Mardanpour and D. H. Hodges, "Passive morphing of flying wing aircraft: Z-shaped configuration," Journal of Fluids and Structures, vol. 44, pp. 17-30, 2014.

[26] P. Gamboa, J. Vale, F. J. P. Lau, and A. Suleman, "Optimization of a morphing wing based on coupled aerodynamic and structural constraints," AIAA Journal, vol. 47, no. 9, pp. 2087-2104, 2009.

[27] J. C. Gomez and E. Garcia, "Morphing unmanned aerial vehicles," Smart Materials and Structures, vol. 20, no. 10, Article ID 103001, 2011.

[28] D. Cadogan, T. Smith, F. Uhelsky, and M. MacKusick, "Morphing wing development for compact package unmanned aerial vehicles," in Proceedings of the 45th AIAA/ASME/ASCE/ AHS/ASC Structures, Structural Dynamics and Materials Conference, AIAA, Palm Springs, Calif, USA, 2004, AIAA Paper 2004-1807.

[29] A. Simpson, N. Coulombe, J. Jacob, and S. Smith, "Morphing wing development for compact package unmanned aerial vehicles," in Proceedings of the 46th AIAA/ASME/ASCE/AHS/ASC Structures, Structural Dynamics and Materials Conference, AIAA, Austin, Tex, USA, 2005.

[30] M. T. Stubbs, Morphing wing development for compact package unmanned aerial vehicles [M.S. thesis], Virginia Polytechnic Institute and State University, 2003.

[31] D. H. Lee and T. A. Weisshaar, "Aeroelastic on a folding wing configuration," in Proceedings of the 46 th AIAA/ASME/ ASCE/AHS/ASC Structures, Structural Dynamics \& Materials Conference, pp. 2452-2464, Austin, Tex, USA, April 2005.

[32] M. P. Snyder, B. Sanders, F. E. Eastep, and G. J. Frank, "Vibration and flutter characteristics of a folding wing," in Proceedings of the 46th AIAA/ASME/ASCE/AHS/ASC Structures, Structural Dynamics and Materials Conference, pp. 2421-2432, AIAA, Austin, Tex, USA, April 2005.

[33] D. R. Bye and P. D. McClure, "Design of a morphing vehicle," in Proceedings of the 48th AIAA/ASME/ASCE/AHS/ASC Structures,
Structural Dynamics, and Materials Conference, pp. 321-336, AIAA, Honolulu, Hawaii, USA, April 2007.

[34] T. G. Ivanco, R. C. Scott, M. H. Love, S. Zink, and T. A. Weisshaar, "Validation of the lockheed Martin morphing concept with wind tunnel testing," in Proceedings of the 48th AIAA/ ASME/ASCE/AHS/ASC Structures, Structural Dynamics, and Materials Conference, pp. 6464-6480, AIAA, Honolulu, Hawaii, USA, April 2007.

[35] J. S. Flanagan, R. C. Strutzenberg, R. B. Myers, and J. E. Rodrian, "Development and flight testing of a morphing aircraft, the NextGen MFX-1," in Proceedings of the 48th AIAA/ASME/ ASCE/AHS/ASC Structures, Structural Dynamics, and Materials Conference, AIAA Paper 2007-1707, pp. 73-75, AIAA, Austin, Tex, USA, April 2007.

[36] G. R. Andersen, D. L. Cowan, and D. J. Piatak, "Aeroelastic modeling, analysis and testing of a morphing wing structure," in Proceedings of the 46th AIAA/ASME/ASCE/AHS/ASC Structures, Structural Dynamics and Materials Conference, AIAA, Austin, Tex, USA, April 2007.

[37] N. Gandhi, A. Jha, J. Monaco, T. M. Seigler, D. Ward, and D. J. Inman, "Intelligent control of a morphing aircraft," in Proceedings of the 46th AIAA/ASME/ASCE/AHS/ASC Structures, Structural Dynamics and Materials Conference, AIAA, Austin, Tex, USA, 2007.

[38] R. Wlezien, G. Horner, A. McGowan et al., "The aircraft morphing program," in Proceedings of the 44th AIAA/ASME/ASCE/ AHS/ASC Structures, Structural Dynamics and Materials Conference, AIAA, Norfolk, Va, USA, 1998.

[39] J. R. Wilson, "Morphing UAVs change the shape of warfare," Aerospace America, vol. 42, no. 2, pp. 28-29, 2004.

[40] J. Dunn, L. Horta, T. Ivanco et al., "Nasa contributions to darpa mas program," in Proceedings of the Aerospace Flutter and Dynamics Council Meeting, NASA Langley Research Center, Hampton, Va, USA, May 2004.

[41] P. J. Attar, D. Tang, and E. H. Dowell, "Nonlinear aeroelastic study for folding wing structures," AIAA Journal, vol. 48, no. 10, pp. 2187-2195, 2010.

[42] I. Wang, S. C. Gibbs, and E. H. Dowell, "Aeroelastic model of multisegmented folding wings: theory and experiment," Journal of Aircraft, vol. 49, no. 3, pp. 911-921, 2012.

[43] D. H. Hodges, Nonlinear Composite Beam Theory, AIAA, Reston, Va, USA, 2006.

[44] "Jetcat spt5 turboshaft engine," Tech. Rep., 2012, http://www .jetcatusa.com/spt5.html. 

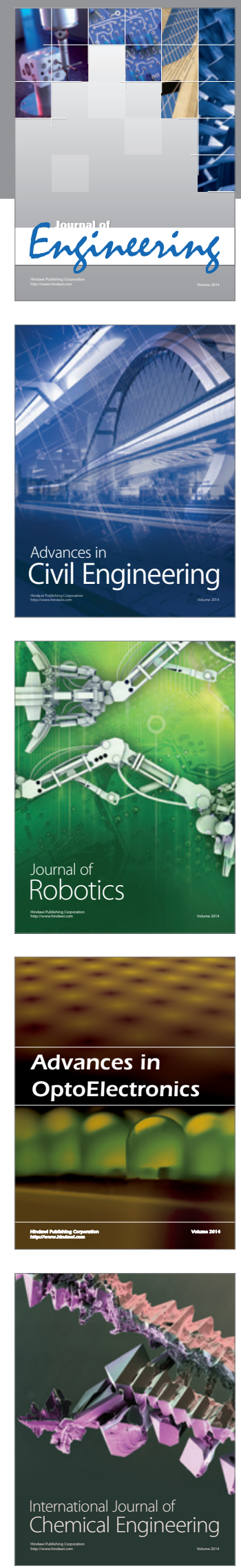

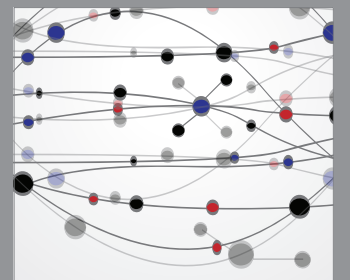

The Scientific World Journal
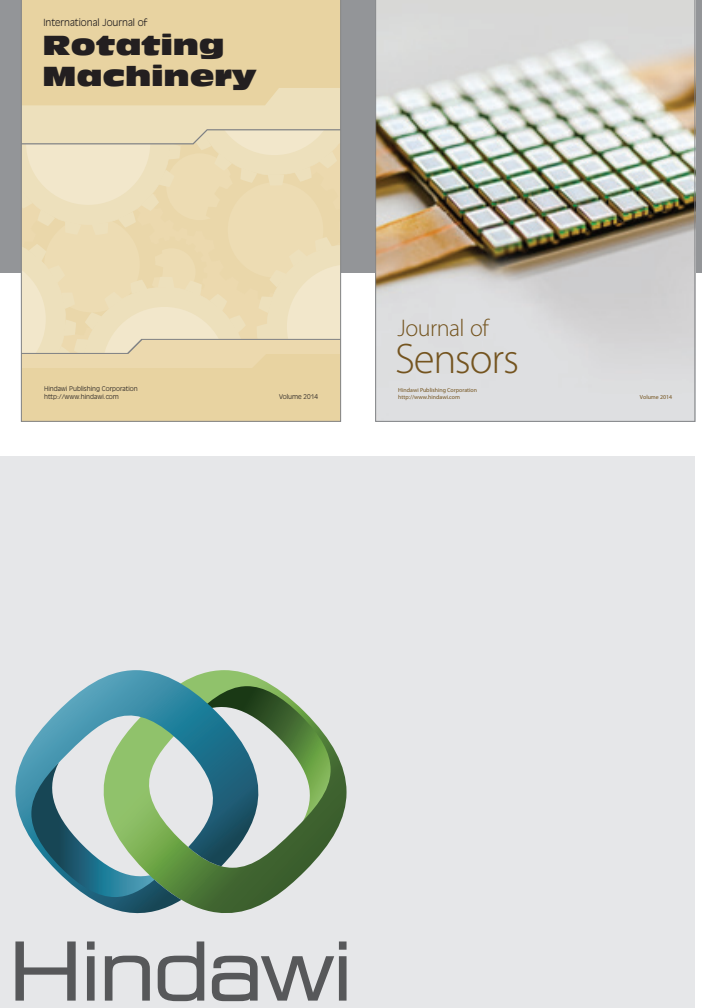

Submit your manuscripts at http://www.hindawi.com
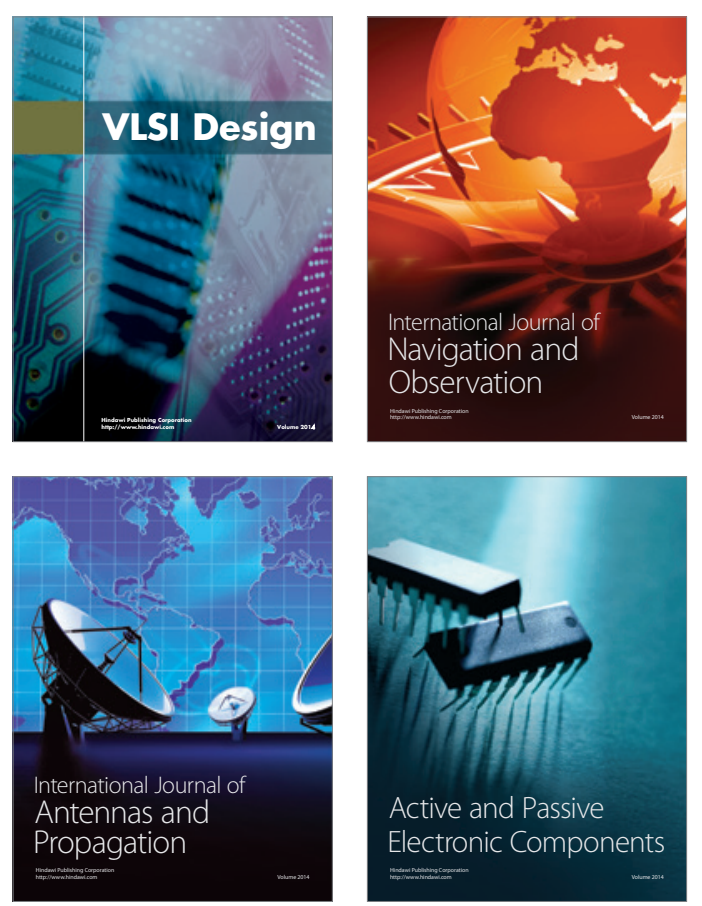
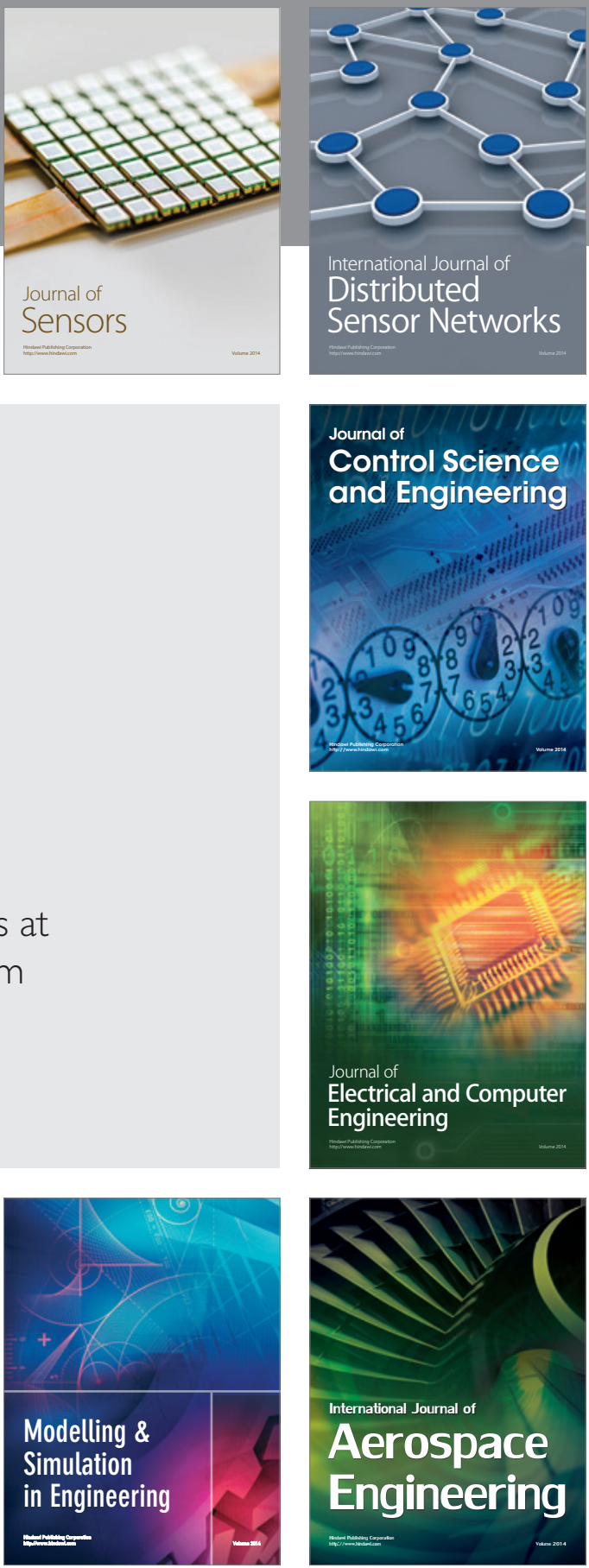

Journal of

Control Science

and Engineering
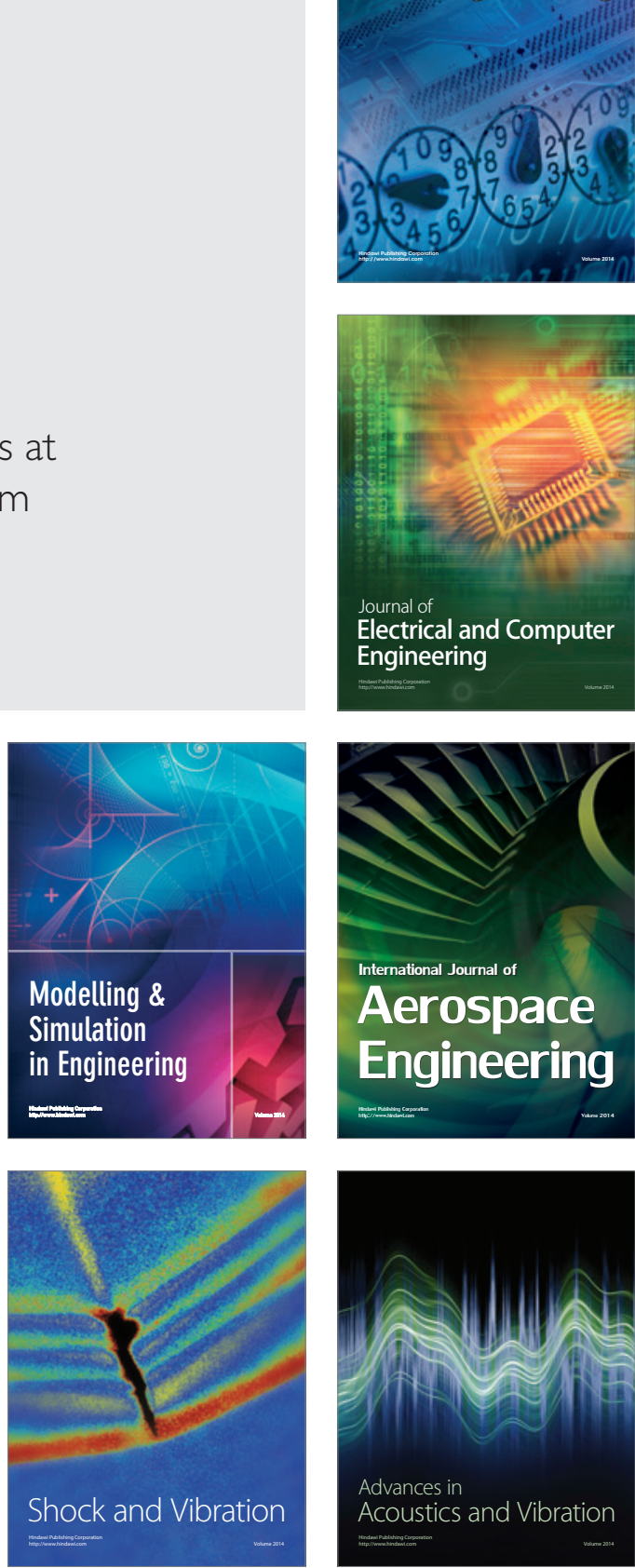